\title{
Stocking Density, Length-Weight Relationship and the Condition of Nile Tilapia in Valley Dam Based Floating Cages in Semi-Arid Karamoja Sub-Region of Uganda
}

\author{
Constantine Chobet Ondhoro ${ }^{1,2, *}$, Moses Ndugwa ${ }^{1}$, Paul Boma ${ }^{1}$, Charles Byaruhanga ${ }^{1}$, \\ George Egau', Paul Okullo ${ }^{1}$
}

${ }^{1}$ Nabuin Zonal Agricultural Research and Development Institute, Moroto, Uganda

${ }^{2}$ Buginyanya Zonal Agricultural Research and Development Institute, Mbale, Uganda

Email address:

occonstantine88@gmail.com (C.C. Ondhoro)

${ }^{*}$ Corresponding author

\section{To cite this article:}

Constantine Chobet Ondhoro, Moses Ndugwa, Paul Boma, Charles Byaruhanga, George Egau, Paul Okullo. Stocking Density, LengthWeight Relationship and the Condition of Nile Tilapia in Valley Dam Based Floating Cages in Semi-Arid Karamoja Sub-Region of Uganda. International Journal of Natural Resource Ecology and Management. Vol. 4, No. 2, 2019, pp. 35-41. doi: 10.11648/j.ijnrem.20190402.11

Received: February 27, 2019; Accepted: April 3, 2019; Published: May 17, 2019

\begin{abstract}
Biological indices; length-weight relationship and fish condition are tools for design of husbandry practices and developing policies for fish farming in natural and artificial water systems. We investigated the effects of fish stocking density treatments; A (100), B (150), C (200) and D (250) fishm ${ }^{-3}$ on growth and well-being of Nile tilapia, reared in floating cages at Arechek valley dam located in Napak District, Karamoja-Uganda. Length-weight relationship and relative condition factor were computed for each treatment and the resultant outputs compared using univariate ANOVA, and regression analyses. Final fish weights ( $( \pm \mathrm{Stdev})$ in different treatments were $311.49 \pm 114.6,204.8 \pm 30.5,138 \pm 40.2$ and $153.3 \pm 68.8 \mathrm{~g}$ while the mean total lengths were $23.29 \pm 2.55 \mathrm{~cm}, 17.5 \pm 5.5,15.6 \pm 15.6$ and $19.4 \pm 3.02 \mathrm{~cm}$, in A, B, C and D respectively. The length-weight allometry was significantly $(P<0.05)$ different among treatments, $\left(\mathrm{F}_{(5,1081)}=3.102\right)$. Mean relative conditions $\left(\mathrm{K}_{\mathrm{n}}\right)$ were ( \pm Stdev) $1.08 \pm 0.08,1.91 \pm 0.13,0.79 \pm 0.08$ and $0.65 \pm 0.08$ in A, B, C and D respectively, and these were significantly different $(P<0.05)$. Water quality parameters did not influence fish growth and $\left.\mathrm{K}_{\mathrm{n}}, \mathrm{F}_{(4,59)}=1.849, P>0.05, \mathrm{R}^{2}=0.111\right)$. The variation in condition was mainly due to stocking density $(P<0.05)$. The most appropriate stocking density of Nile tilapia in valley dam using $35 \%$ C. P sinking feed is $100-150$ fishm $^{-3}$ of cage.
\end{abstract}

Keywords: Growth, Fish Well-being, Aquaculture Policy

\section{Introduction}

Nile tilapia (Oreochromis niloticus) is the principle farmed fish species in Uganda and is among the most favorable commodity for cage fish culture in the world [1,2]. The fish is perhaps the most highly favored species for intensive culture across the different production systems (cages, earthen ponds, and concrete tanks) due to its flexibility to ecological dynamics and tolerance to a wide variation in the quality of artificial feeds [3]. However, commercial production of Nile tilapia is still limited by lack of policy guidelines on the stocking density $\left(\mathrm{kgfishm}^{-3}\right)$ of cage, especially in valley dams, where no substantial studies have been done in Uganda.

A valley dam is a structure or barrier constructed across a valley, to conserve, store or to control the flow of water. The water may be used for domestic water supplies, irrigation, watering terrestrial livestock, fish farming or environmental conservation in water-stricken areas [2, 3]. In Karamoja subregion, several valley dams were originally used for crop irrigation and watering livestock. The introduction of cage fish farming into these dams is an afterthought activity to compliment agricultural output of the dams in availing the much-needed fish protein to vulnerable groups in a hard-toreach area [3]. The success of the introduction of fish farming in valley dams requires strong technical guidelines to safeguard environmental quality and make the enterprise 
economically sound.

Arechek valley dam is located in Napak District in the semi-arid area of Karamoja, where rainfall distribution is not reliable; the dam is heavily crowded by large herds of livestock which draw water from the facility on daily basis. The region is sparsely populated due to high level of infant and maternal mortalities, which stand at 64 deaths per every 1000 live birth [4]. The high infant and maternal mortalities are motivated by among others malnutrition. The area largely relies on cattle products such as milk and beef but this of late has become insufficient in quantity and unreliable in quality compared to fish [4].

Amidst the raging challenges of prolonged drought, inadequate food supply and malnutrition, the Karamoja community has no sustainable source of food fish, yet fish protein is known to be nutritious and superior in terms of supply of essential amino acid (lysine) and omega-3fatty acid [4]. One way of ensuring sustained supply of food fish to Karamoja region is through promotion of fish farming to augment the use of the valley dam and ensure constant supply of fish to the community. However, sustainability of fish farming in a given locality requires the fish being cultured to be suitable for culture in the local environment, and with minimum environmental effects [4]. Ascertaining the correct number of fish stocked per unit volume of water, facilitates proper planning of the quantity of production, both in terms of seed and other inputs like feeds and even labor [1].

However, for commercial operations, the important parameter in gauging the well-being of a fish under different stocking densities in cages is the relationship between individual fish length and its total weight [1]. This approach also examines the possible differences between individuals among experimental treatments, consisting of the same species of fish [1]. Furthermore, length-weight relationship provides important insight into the condition and growth patterns of fish $[5,6]$. It is also an important aspect that guides farmers in achieving commercially viable fish sizes at harvest [7].

Condition factor signifies the overall well-being and health of a fish stock. It is an important factor in signaling growth in relation to stocking density. Condition factor of farmed fish will decrease with increase in individual fish length, hence providing a tool for monitoring physiological status of the fish $[5,8]$. Therefore; condition factor is a tool useful in monitoring the effects of density dependent factors on fish population [9].

Although the relationship between length and weight of Nile tilapia has been studied elsewhere for different production systems, there is no information available from a similar study conducted in cages placed in valley dams. Yet the introduction of cage fish farming in Karamoja sub-region in particular, will require policy guidelines in terms of fish stocking density in respect to species, and possible environmental and economic out comes. Therefore, this study investigated the effects of stocking density on LengthWeight Relationship and condition with a view of generating information on appropriate stocking density to guide fish farms and the government to farm profitably, and mitigate negative environmental disasters such as water pollution, associated with inappropriately high stocking density.

\section{Materials and Methods}

\subsection{Study Area}

The study was conducted in Arechek valley dam located at Matany sub-county, Napak District, Karamoja sub-region in Uganda. With a surface area of $4 \mathrm{~km}^{2}$, the dam is established along a valley traversing three districts of Nakapiripirit, Napak and Katakwi. Owing to its location in a range land, where bush burning is common, the dam is often enriched by organic matter, a precursor for algal development. The average depth of the dam is five meters (Figure 1).

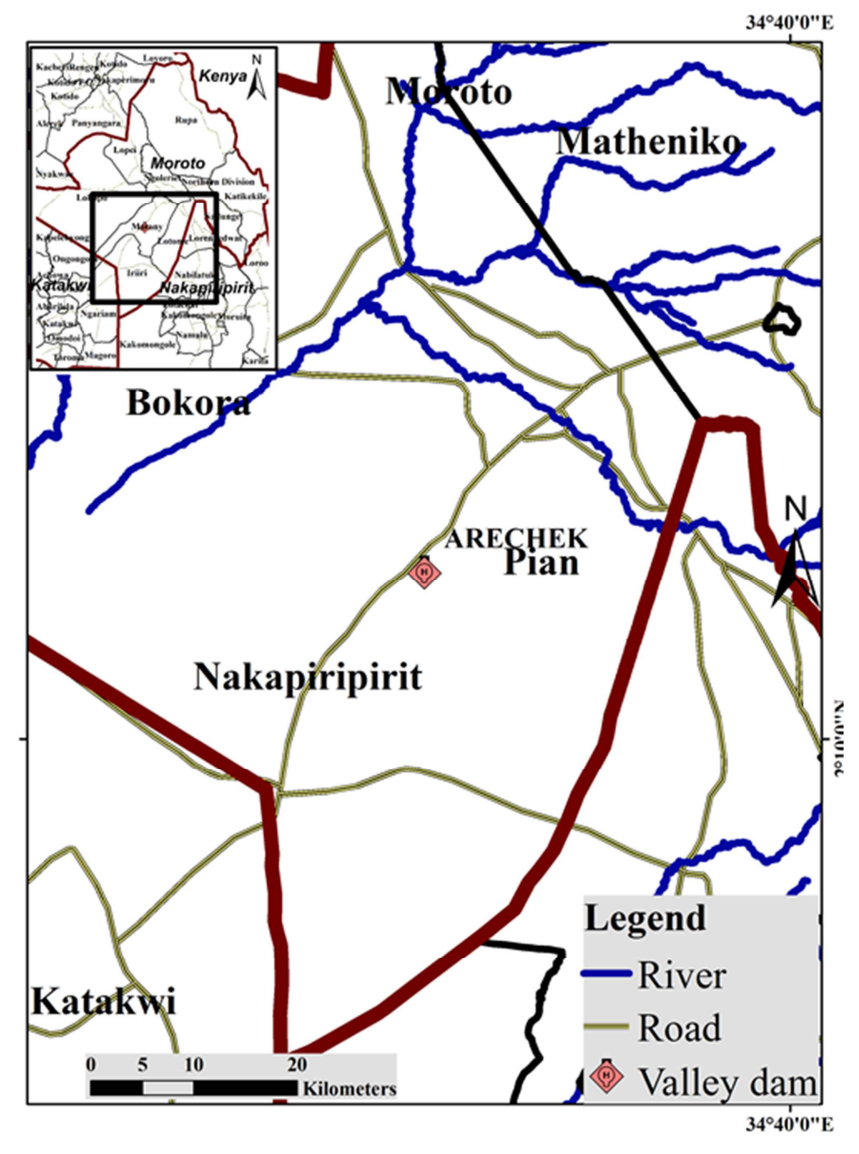

Figure 1. Map showing the location of Arechek valley dam (marked pink) in Napak District of Karamoja sub-region, where the experiment on stocking density, length-weight relationship and condition was conducted. The blue ribbons represent the nearby streams and rivers neighboring he study site respectively.

\subsection{The Experiment}

Four experimental treatments A $\left(100 \mathrm{fishm}^{-3}\right)$, B (150 fishm $\left.{ }^{3-}\right), C\left(200 \mathrm{fishm}^{-3}\right)$ and $\mathrm{D}\left(250 \mathrm{fishm}^{-3}\right)$, were set up in triplicates using floating cages, each $8 \mathrm{~m}^{3}$ by volume (dimension; $2 \times 2 \times 2$ ). The cages were placed offshore a valley dam, at a location with water depth average five meters. Nile 
tilapia fingerlings of nearly the same body size were obtained from commercial fish hatchery within the country for experimentation. Before the beginning of the experiment, the fish were stocked in two separate cages and fed for a month in order to acclimatize the stock to dam environment (water quality and experimental feed). To the four experimental treatments (A, B, C and D), tilapia fingerlings (initial average weight, $2.53 \pm 1.20 \mathrm{~g}$ ) were fed on commercial sinking pellets (35\% crude protein) for five months growth period from August 2017 to January 2018. The size of the experimental feed pellets initially comprised $1.5 \mathrm{~mm}$ diameter but this was changed to 2 and $3 \mathrm{~mm}$ respectively, following the observed fish gape (mouth) size. The feed was being stored in sacks placed on wooden pallets in a well aerated room with concrete walls and floor to minimize deterioration of the feed quality.

\subsection{Fish Feeding}

Fish were fed to satiation thrice a day at $0900 \mathrm{hrs,} \mathrm{1200-}$ $1400 \mathrm{hrs}$ and 1500-1700 hrs.

\subsection{Fish Sampling}

Biometric and water quality data were taken monthly for five months. During sampling, a sub-sample of 50 fish was randomly drawn from each experimental unit for biometric data collection. For each sampled fish, total weight, total and standard lengths were taken. Fish weight (g) was taken using a digital electronic scale; model Constant 14192-007R, while standard and total lengths $(\mathrm{cm})$ were taken using fish measuring board, model Bakelite translucent graduated board, $100 \mathrm{~cm}$ long.

\subsection{Environmental Quality Monitoring}

Water quality measurements were done on-spot between $0800 \mathrm{hrs}$ and $0900 \mathrm{hrs}$ on each sampling day, using a multiparameter water quality test meter, model Eco-Sense DO200A. Reading for each parameter was taken from two locations (in and outside each cage/experimental unit). The parameters taken were temperature (degrees Celsius), Dissolved oxygen (ppm) and $\mathrm{pH}$.

\subsection{Computation of Length-weight Relationship and the Condition Factor}

To compare condition among treatments and for the generation of predictive models of fish condition, relative condition factor of Nile tilapia was calculated as the ratio of observed individual fish weight to expected weight of an individual of a given length. For this, we applied the formula: $\mathrm{K}_{\mathrm{n}}=\mathrm{W}_{\mathrm{i}} / \mathrm{aL}_{\mathrm{i}}^{\mathrm{b}}$; where $\mathrm{W}_{\mathrm{i}}$ is observed individual fish weight, $\mathrm{L}_{\mathrm{i}}$ is observed individual fish total length, and, $a$ and $b$ are species-specific constants [10]. These regression constants were obtained from the treatment length-weight relationship $\left(\mathrm{W}=\mathrm{aL}^{\mathrm{b}}\right)$ derived by pooling data generated from the respective treatment replicates in successive sampling months for the entire fish specimen in each treatment. Length and weight data were log-transformed to remove skewedness, and the resulting linear relationships fitted by least square regression using weight as the dependent variable.

\subsection{Statistical Analysis}

The condition factor and water quality was compared to assess the health of Nile tilapia in different stocking densities. The mean relative condition of fish in each treatment replicates were pooled and computed to explore relationships between fish stocking densities and fish condition. Univariate Analysis of Variance (ANOVA) was used to test for differences in mean relative condition of fish in each treatment exposed to different stocking densities. To explore the effects of water quality and stocking density on fish condition, multiple regression analysis was performed, by fitting relative condition factor $\left(\mathrm{K}_{\mathrm{n}}\right)$ against water quality variables and stocking density. Statistical analysis was done using SPSS for windows version 21 at $0.05 \%$ level of significance [11].

\section{Results and Discussion}

\subsection{Fish Growth}

In the five months growth period, mean final fish weights ( \pm Stdev) in the different treatments were $311.49 \pm 114.6 \mathrm{~g}$, $204.8 \pm 30.5 \mathrm{~g}, 138 \pm 40.2 \mathrm{~g}$, and $153.3 \pm 68.8 \mathrm{~g}$, while the mean fish total lengths were $23.29 \pm 2.55 \mathrm{~cm}, 17.5 \pm 5.5,15.6 \pm 15.6$, and $19.4 \pm 3.02$, and, in the treatments $\mathrm{A}\left(100 \mathrm{fishm}^{-3}\right), \mathrm{B}(150$ fishm $\left.^{-3}\right), \mathrm{C}\left(200 \mathrm{fishm}^{-3}\right)$ and D (250 fishm $\left.{ }^{-3}\right)$ respectively. Stocking density has become a widely applicable and guiding husbandry factor in intensive fish culture in earthen ponds, concrete tanks, raceways and cages. The concept of stocking density relates to the concentration at which fish are initially stocked and implies the intensity of fish at a given time [12, 13]. Stocking density is often defined in terms of kilogram per cubic meter $\left(\mathrm{kgm}^{-3}\right)$ of the water, reflecting a weight/mass-volume relationship.

For a given production system, stocking density depends on the carrying capacity, thereby determining the maximum quantity of fish the system can sustain without compromising the well-being of the organism, providing an opportunity for management policy formulations [3].

In this study, fish held in cages with lower densities were heavier than the ones with higher densities. Thus, the fish in cages $\mathrm{A}$ and $\mathrm{B}$, of stocking densities $100 \mathrm{fishm}^{3-}$. and 150 fishm $^{3-}$, were heavier (mean weight $311.49 \pm 114.6 \mathrm{~g}$ and $204.8 \pm 30.5$, respectively) than fish in cages C and D (stocking densities $200 \mathrm{fishm}^{3}$ and $250 \mathrm{fishm}^{3}$ ) with final weights of $138 \pm 40.2$ and $153.3 \pm 68.8 \mathrm{~g}$ respectively after a five-months growth period. The heavier fish obtained at lower stocking density was also reflective of the significant variation in the relationship between length and weight across the experimental treatments A, B, C and D.

\subsection{Length-weight Relationship}

Post-hoc test showed significant differences $(P<0.05)$ in the relative condition factor among fish of the four different 
treatments. No significant difference, however, was observed between the treatments $\mathrm{C}$ and $\mathrm{D}$ (Mean diff $0.75, P=1.0$ ). The length-weight allometry among treatments was also significantly $(P<0.05)$ different, $\left(\mathrm{F}_{(5,1081)}=3.102, P<0.009\right)$. The relationship between weight and length for fish in each treatment, obtained by the regression of length and weight of individuals across treatments was significant $(P<0.001)$. The proportion of the variance in individual treatment fish weights that was due to change in fish length was significantly $(P<0.001)$ different across the treatments. Thus,
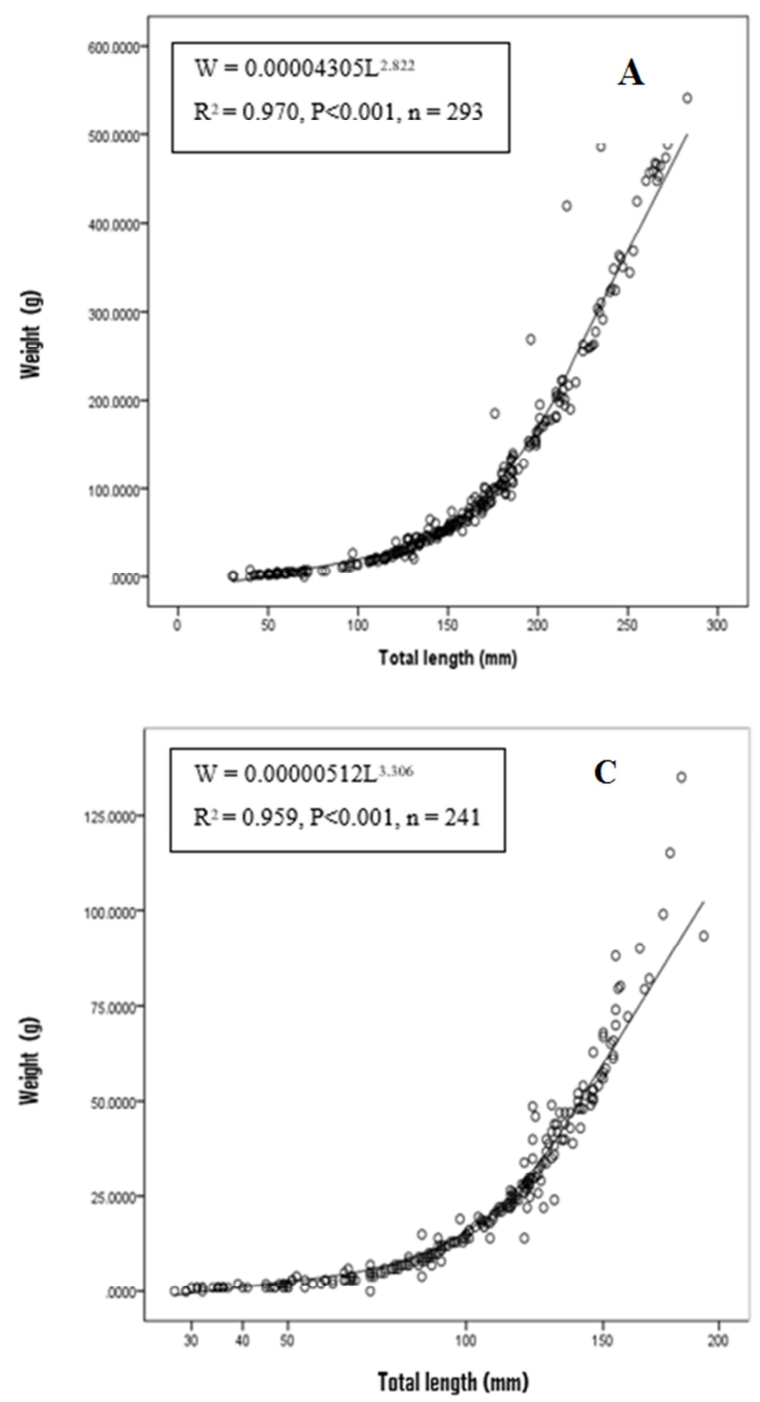

the ' $b$ ' values that represent the predicted fish total length in treatments A and B were not significantly different from each other but significantly different from those of treatments B and $\mathrm{C}$. Deviation from the widely accepted values $\mathrm{b}=3$, and the higher coefficient of determination $\left(\mathrm{R}^{2}>60 \%\right)$ in all cages depict significant variation in the length-weight relationship. Treatments $\mathrm{A}$ and $\mathrm{B}$ experienced negative allometry, with ' $b$ ' values of 2.82; and 2.85 and, while fish in cages $\mathrm{C}$ and $\mathrm{D}$, experienced positive allometry; $\mathrm{b}=3.3$; and $\mathrm{b}=3.3$ in $\mathrm{C}$ and $\mathrm{D}$ respectively (Figure 2 ).
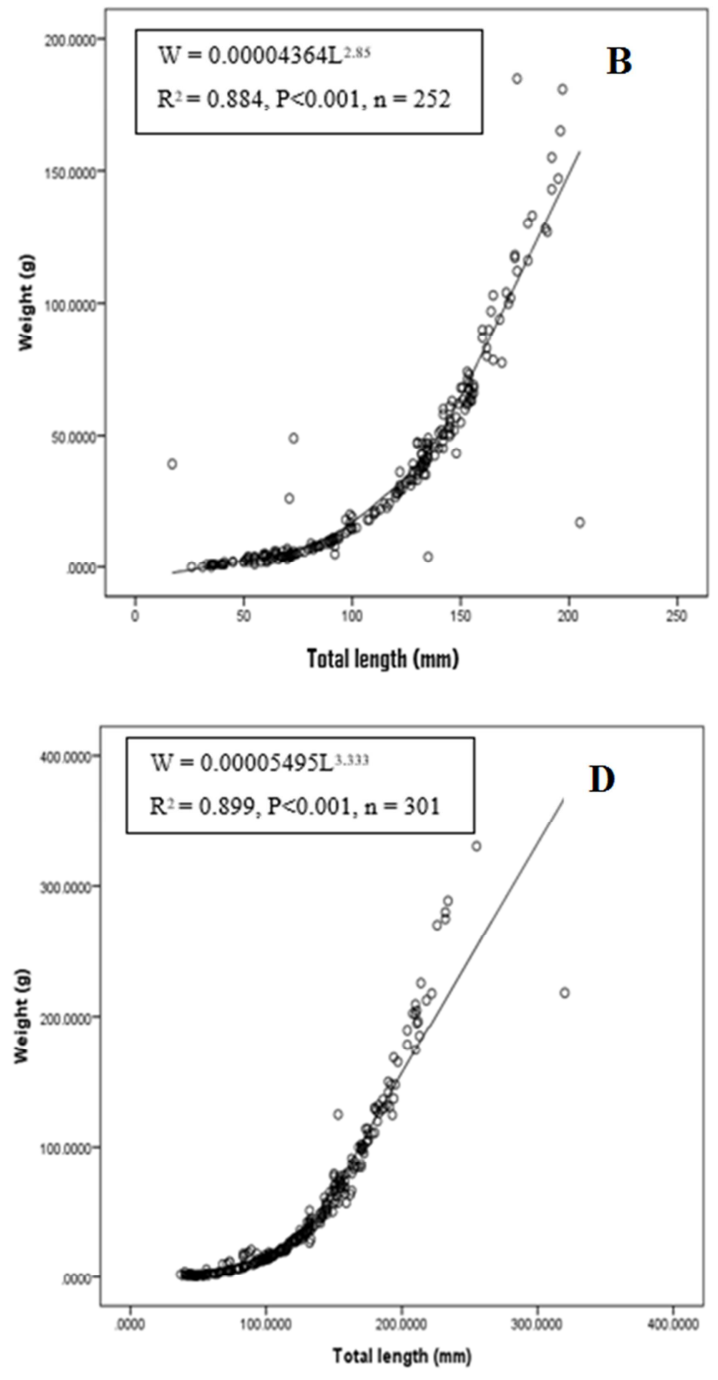

Figure 2. Relationship between total weight $(\mathrm{g})$ and total length $(\mathrm{mm})$ for Nile tilapia derived after regression of length and weight of individuals in each treatments data of all sampled individuals at Arechek valley dam, Napak district. The treatments were distributed in four experimental treatments, with each treatment cages/units $A, B, C$ and D, replicated in triplicates with stocking densities of 100, 150, 200 and 250 fishm ${ }^{-3}$ respectively.

Growth is said to be positively allometric when weight of an organism increases more than length $(b>3)$ and negative when length increases more than weight $(b<3)$ as was the case with cages A and B $(b<3)$ and $B$ and $C(b>3)$ [14]. However, for farmed fish to acquire reasonable market quality there is need for proportional increase in both length and weight. Otherwise, shorter fish would equally weigh less the same way slender counter parts would.

The results conform to the observation made elsewhere that a fish normally does not retain the same shape or body conformity across the different life stages and specific gravity of tissues does not remain the same $[10,5]$. Hence the actual relationship departs significantly from the cub law. This variation in the length-weight relationship may not only be attributed to differences in stocking density, but also sample size variation, growth stages and environmental factors [14].

Whereas fish attained smaller sizes, weights in treatments 
$\mathrm{C}$ and D with higher stocking density had positive allometry; this may be due to uniformity in sizes and very low variance among individuals. In addition, several advantages are attributed to higher stocking density in tilapia monoculture such as; fostered faster growth rates, homogeneity in sizes, reduced cannibalism in fingerlings and juveniles [13].

\subsection{Relative Condition Factor $\left(K_{n}\right)$}

Mean relative condition $\left(\mathrm{K}_{\mathrm{n}}\right)( \pm$ Stdev) for the respective treatments $(P<0.05)$ were $1.91 \pm 0.13,1.08 \pm 0.08,0.79 \pm 0.08$, and $0.65 \pm 0.08$ in treatments $\mathrm{A}, \mathrm{B}, \mathrm{C}$ and $\mathrm{D}$ respectively (Figure 3).

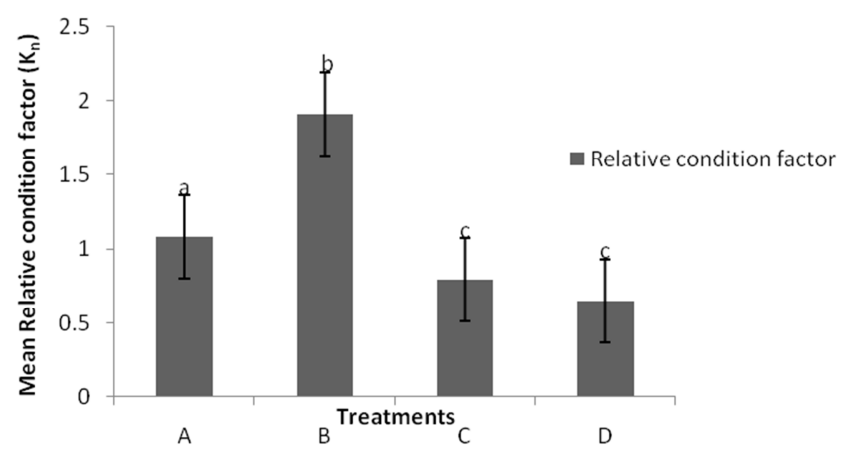

Figure 3. Mean relative condition of Nile tilapia derived after regression of length and weight of individuals in four treatments for all sampled individuals at Arechek valley dam, Napak district. The treatments were distributed in experimental units (cages $A, B, C$ and D). Experiment $A, B, C$ and $D$ represent the different stocking densities 100, 150, 200 and 250 fishm ${ }^{3}$ respectively. Vertical bars represent \pm 1 standard deviation. Different letters above each treatment indicates significant difference at $P<0.05$.

Condition factor represents a quantitative indicator of the well-being of fish [15]. For the current study, fish were reared purposely to provide food and perhaps generate income for the farmer. However, production and income generation in fish farming greatly depend on the quality and quantity of fish produced. In this regard, the statistically significant variation in relative condition $\left(\mathrm{K}_{\mathrm{n}}\right)$ with stocking density, across the different treatments is reflective of the role stocking density plays in determining the quality and quantity of fish produced from a given production system. Similarly, the highest condition and hence better condition of Nile tilapia was obtained from cage $\mathrm{B}$, followed by $\mathrm{A}$, while the worst condition of 0.65 being in cage $\mathrm{D}$ which also had the highest stocking density. The latter observation indicates that higher stocking density reduces the vigor of the stock to attain bigger weight, and therefore, stocking density beyond 150 fishm $^{-3}$ is not appropriate for valley dams. This perhaps is because of the closed nature and the location of the system in semi-arid area where water exchange in the system is minimal. It has also been observed that changes in food reserve in farmed fish occur due to restricted access to feeds by individual fish resulting from competition. Overcrowding especially in cages creates stratification and territories of different sizes due to difference in growth, emanating in individuals' ability to access food. Thus, other than at fry/fingerling stage when higher stocking helps in regulating cannibalism in Nile tilapia, the practice becomes a vice at juvenile to adult stages as more aggressive behavior by much bigger individuals commonly known as "shooters" become apparent [16]. As observed therefore, the relative condition index in higher stocking densities $\mathrm{C}$ and $\mathrm{D}$ were below the threshold value of one, meaning stocking density of $\geq 150$ fishm $^{-3}$ leads to less robust fish at harvest, compared to a lower stocking density of $\leq 150 \mathrm{fishm}^{-3}$. Stocking density has also been shown to affect fish health and condition, therefore, condition is one of the fundamental principles that determine the carrying capacity of different production systems $[13,17$, $18]$.

Furthermore, as individuals in confinement continue to increase in size (length and weight); the volume of the cage continues to reduce, reaching carrying capacity at smaller size of fish. Crowded systems are associated with physiological stress and body injuries such as scale loss, fin damages, and opportunistic disease infections [13, 19]. Yet stress in farmed fish is also associated with reduced appetite, low food conversion and hence low body weight. The negative consequence of higher stocking density often results in poor quality fish products with lower economic returns to the farmer.

\subsection{Effects of Water Quality and Stocking Density on Relative Fish Condition}

Mean water quality parameters did not vary significantly among treatments $(P>0.05)$. The observed variation in mean relative condition among treatments was not influenced by water quality parameters $\mathrm{K}_{\mathrm{n}}, \mathrm{F}(4,59)=1.849, P>0.05, \mathrm{R}^{2}=$ $0.111)$. Thus, the variation in mean relative condition was mainly due to stocking density $(P<0.05)$ (Table 1$)$.

Table 1. Mean levels \pm Stdev of the physico-chemical water quality parameters in the different cage culture treatments.

\begin{tabular}{llllll}
\hline \multirow{2}{*}{ Water quality parameters } & \multicolumn{2}{l}{ Levels in different treatments } & \multicolumn{3}{c}{ Benchmark for fresh water fish culture } \\
\cline { 2 - 6 } & A & B & C & D & \\
\hline Dissolved oxygen $\left(\mathrm{mgL}^{-1}\right)$ & $4.8 \pm 1.1$ & $4.8 \pm 1.2$ & $4.9 \pm 1.3$ & $4.9 \pm 1.3$ & $\geq 5[12]$ \\
Water Temperature $\left({ }^{\circ} \mathrm{C}\right)$ & $25.5 \pm 1.3$ & $25.4 \pm 1.5$ & $25.3 \pm 1.6$ & $25.3 \pm 1.7$ & $25-30[12]$ \\
Hydrogen potential $(\mathrm{pH})$ & $7.3 \pm 0.4$ & $7.3 \pm 0.4$ & $7.3 \pm 0.4$ & $7.3 \pm 0.4$ & $6.5-8.5[12]$ \\
\hline
\end{tabular}

The treatments were distributed in four experiments units, cages A, B, C and D, with different stocking densities of 100 , 150,200 and 250 fishm-3 respectively.

Considering environmental factors, there was no evidence of significant effects of water quality on fish length-weight relationship and condition. All the parameters were within the same range across all the treatment and therefore, the 
same impacts were shared across the treatments. All the differences in growth, and condition were mainly attributed to variation in fish stocking density among others. This study may also be replicated in crater lakes since they seem to have similar ecological dynamics.

\section{Conclusion and Recommendations}

This study defined appropriate stocking density of Nile tilapia in valley dam using sinking feeds $35 \% \mathrm{C}$. P as being in the range of $100-150$ fishm $^{-3}$ of cage. Given the numerous valley dams in the region, the present findings could form a baseline for regulatory policy for sustainable cage culture in these water bodies of Uganda. We recommend further studies using floating feeds, with cages placed in different locations for comparison.

\section{Acknowledgements}

Financial support for this study was provided by the National Agricultural Research Organization-Uganda through the Agricultural Technology and Agri-business Advisory Services (ATAAS) project (P.109224). We sincerely acknowledge the Director of Research at Buginyanya Zonal Agricultural Research and Development Institute for providing the team with transport throughout the trials. Sincere appreciation to Dr. Effitre Jackson of Makerere University, for advice on statistical analysis, the field staff; Mr. Paul Lojok and Mr. Abura for guidance and coordination at the dam in Napaki District. We thank all the technicians and transport officers led by Mr. Faustine Odeke and Mr. Gerald Woniala respectively, for the support during the experiment. Special thanks to Mr. Martin Turyashemererwa of the National Fisheries Resources Research Institute (NaFIRRI)-Aquaculture Research and Development Centre (ARDC) at Kajjansi for the information and communication technology (ICT) support.

\section{References}

[1] Ighwela, K. A., Ahmed, A. B., \& Abol-Munafi, A. B. (2011). Condition factor as an indicator of growth and feeding intensity of Nile tilapia fingerlings (Oreochromis niloticus) fed on different diets of maltose. Journal of Agricultural and environmental science, https://www.idosi.org/aejaes/jaes11(4)11/17.pdf 11(4):559-563.

[2] Food and Agricultural Organization-FAO. (2016). The State of World Fisheries and Aquaculture 2016, Rome, Italy 200pp. retrieved from http://www.fao.org.html.

[3] Sadek, S. (2013). Site selection and carrying capacity estimates for inland and coastal aquaculture in the Arab Republic of Egypt. In L. G. Ross, T. C. Telfer, L. Falconer, D. Soto \& J. Aguilar Manjarrez, eds. Site selection and carrying capacities for inland and coastal aquaculture. Stirling, the United Kingdom of Great Britain and Northern Ireland pp. 183-196. http://www.fao.org/3/a-i3322e.pdf.

[4] Uganda Bureau of Statistics-UBOS. (2016). Uganda
Demographic and Health Survey 2016. Key indicators report, March 2017, Kampala. Retrieved from: https://www.ubos.org/onlinefiles/uploads/ubos/pdf\%20docume nts/Uganda_DHS_2016_KIR.pdf.

[5] Efitre, J., Chapman, L. J., \& Murie, J. D. (2009). Fish condition in introduced tilapias of Ugandan crater lakes in relation to deforestation and fishing pressure. Environmental Biology of Fishes, 85(1), 63-75. http://doi:10.1007/s10641-009-9461-z.

[6] Ogutu-Ohwayo, R., Odongkara, K., Okello, W., Mbabazi, D., Wandera, S. B., Ndawula, L. M., \& Natugonza, V. (2013). Variations and changes in habitat, productivity, composition of aquatic biota and fisheries of the Kyoga lake system: lessons for management. African Journal of Aquatic Science, 38(1), 1-14. http://do:10.2989/16085914.2013.795886.

[7] Nehemia, A., Maganira, J. D., \& Rumisha, C. (2012). LengthWeight relationship and condition factor of tilapia species grown in marine and fresh water ponds. Agriculture and biology journal of North America, 3(3), 117-124. http://doi:10.5251/abjna.2012.3.

[8] Ondhoro, C. C., Masembe, C. Maes, G. E., Nkalubo, W. N., Walakira, J. K., Naluwairo, J., \& Efitre, J. (2016). The condition factor, Length-Weight relationship and the associated parameters of Barbus altianalis (Boulenger, 1900) fishery in Lakes Victoria and Edward basins of Uganda. Environmental Biology of Fishes, 100(2), 99-110. https://doi.org/10.1007/s10641-016-0540-7.

[9] Lloret, J., Gilde Sola, L., Souplet, A., \& Galzin, R. (2002). Effects of large-scale habitat variability on condition of demersal exploited fish in the north-western Mediterranean. ICES Journal of Marine Science, 2002(59), 1215-1227. http://doi:10.1006/jmsc.2002.1294.

[10] Le Cren, E. D. (1951). The length-weight relationship and seasonal cycle in gonad weight and condition in Perch (Perca fluviatilis). Journal of Animal Ecology, 20(2), 201-219. http://dx.doi:10.2307/1540.

[11] Field, A. P., \& Wilcox, R. R. (2019). Robust statistical methods: a primer for clinical psychology and experimental psychopathology researchers. Behavior Research and Therapy, 98:19-38. https://doi.org/10.1016/j.brat.2017.05.013.

[12] Boyd, C. E. (1998). Water quality for pond aquaculture: Research and Development. Auburn University, Alabama the United States of America. Series No.43. http://soiltesting.tamu.edu/publications/AU43.pdf.

[13] Bassey, A. U., \& Ajah, P. O. (2010). Effect of three Feeding Regimes on Growth, Condition Factor and Food Conversion rate of Pond Cultured Parachanna obscura (Gunther, 1861) (Channidae) in Calabar, Nigeria. Turkish Journal of Fisheries and Aquatic Sciences, 10:195-202. http://doi:10.4194/trjfas.2010.0206.

[14] Datta, S. N., Kaur, V. I., Dhawan, A., \& Jassal, G. (2013). Estimation of length-weight relationship and condition factor of spotted snake head Channa punctata (Bloch) under different feeding regimes. SpringerPlus, 2013(2):431-436. https://doi.org/10.1186/2193-1801-2-436.

[15] Chambel, J., Severiano, V., Batista, T., Mendes, S., \& Redrosa, R. (2015). Effects of stocking density and different diets on growth of Percula Clownfish, Amphiprion percula (Lacepede, 1802). Springer Plus, 2015(1), 174-183. https://doi.org/10.1186/s40064-015-0967-x. 
[16] Mollah, M. F. A. Islam, M. S., Faroque, M. A. A., \& Khan, M. H. K. (1999). Minimization of cannibalism of African catfish (Clarias gariepinus Burchell) larvae in indoor culture system. Bangladesh Journal of Fisheries Resources, 6(3), 181-186. http://dx.doi.org/10.17017/jfish.v6i1.2018.280.

[17] Bortone, S. A. (2003). Biology of the spotted sea trout: CRC Marine Biology Series. Boca Raton-Florida, the United States of America. CRC Press., 328pp. https://www.crcpress.com.
[18] Ashley, P. J. (2007). Fish well-fare: current issues in aquaculture. Journal of applied animal behavior science, 104(4), 199-235. http://dx. doi:10.1016/j.applanim.2006.09.001.

[19] Cajas, R. F. C., Selz, O. M., Ripmeester, R. A. P., Seehausen, O., \& Maan, M. E. (2012). Species-specific Relationships between water transparency and male coloration within and between two closely Related Lake Victoria Cichlid Species. International Journal of Evolutionary Biology, 2012(1), 1-12. http://doi:10.1155/2012/161306. 